\title{
Hepatitis A Outbreak in a Facility for the Disabled, Gyeonggi Province, Korea: An Epidemiological Investigation
}

\author{
Yeonhwa Chang', Chanhee Kim', Nayoung Kim², Joon Jai Kim ', Heeyoung Lee ${ }^{3}$ \\ ${ }^{1}$ Infectious Disease Control Center, Gyeonggi Provincial Government, Suwon, Korea; ${ }^{2}$ Regional Centers for Disease Control and Prevention, Korea \\ Disease Control and Prevention Agency, Seoul, Korea; ${ }^{3}$ Korea Center for Preventive Medicine and Public Health, Seoul National University Bundang \\ Hospital, Seongnam, Korea
}

Objectives: The number of cases of hepatitis A virus (HAV) infections has sharply increased in Korea, especially among young adults. In this study, an HAV outbreak in a facility for disabled people was investigated, and we found epidemiological differences both between 2 different generations and between generally abled and disabled groups.

Methods: We analyzed the incubation period and attack rate of an HAV outbreak and investigated the prevalence of HAV antibodies among the staff and residents of a facility for the disabled. We performed a retrospective cohort study during the HAV outbreak, which lasted from February 8 to 25, 2019, including examinations of HAV antibody tests and post-exposure HAV vaccination for the staff or residents of the facility.

Results: There were 9 confirmed cases in 2 staff members and 7 residents. Among 53 people ( 30 staff and 23 residents), except for the 9 confirmed cases and 1 staff member with a known history of HAV infection, HAV seroprevalence was seen in $16.7 \%$ of the staff under 40 years of age and $95.2 \%$ of those over 40 years of age, while the corresponding rates in the residents were $0.0 \%$ and $58.8 \%$, respectively.

Conclusions: This result implies that it is necessary to prioritize HAV vaccination for vulnerable groups and workers of residential care facilities.

Key words: Hepatitis A, Immunization, Vaccination, Seroepidemiologic studies

\section{INTRODUCTION}

Hepatitis A virus (HAV) is a single-stranded RNA virus belonging to the Picornaviridae family [1-4]. There are 7 genotypes of HAV, 4 of which (I, II, III, IV) induce infection in the hu-

Received: June 22, 2021 Accepted: August 11, 2021

Corresponding author: Heeyoung Lee

Korea Center for Preventive Medicine and Public Health, Seoul National University Bundang Hospital, 82 Gumi-ro 173beon-gil,

Bundang-gu, Seongnam 13620, Korea

E-mail: wanderingstone@gmail.com

This is an Open Access article distributed under the terms of the Creative Commons Attribution Non-Commercial License (https://creativecommons.org/licenses/bync/4.0// which permits unrestricted non-commercial use, distribution, and reproduction in any medium, provided the original work is properly cited. man body $[1-3,5,6]$. HAV is transmitted by contaminated food or water and has an average incubation period of 28 days (range, 15-50) [1,7-9]. The clinical symptoms of HAV vary from mild to severe, and in symptomatic cases, dark urine and jaundice appear rapidly after the initial manifestation of systemic symptoms such as fever, headache, and fatigue $[8,10]$.

In Korea, HAV infection is managed as a grade 2 communicable disease. Although HAV infection is preventable by vaccination, the number of cases of HAV infection has sharply increased recently in Korea [11-13]. Additionally, the prevalence of HAV infection in young adults accounts for a large proportion of the HAV infection burden in Korea [3,10,12,14-16]. This might be because general hygienic conditions have improved over the years; therefore, young adults have not been provid- 
ed the opportunity to acquire natural immunity against HAV infection [10,17-19].

In this study, we investigated an HAV outbreak in a facility for disabled individuals, wherein we found epidemiological differences both between 2 different generations (aged under and over 40 years) and between generally abled and disabled groups. These results can be used as evidence to establish public health strategies, especially for prioritizing vulnerable groups to prevent HAV infection in Korea.

\section{METHODS}

\section{Identification of the Outbreak}

On February 18, 2019, the index case (a resident of facility A) of an HAV infection outbreak in facility A was reported to the Paju Health Center. The facility's regular physician treated the index case's fever and fatigue, and transferred him to a local medical facility. General laboratory tests were carried out for the index case, including an immunoglobulin M (IgM) anti-HAV test, and the individual was diagnosed with HAV infection on February 18, 2019. After 3 days, 1 more case was confirmed and 2 more were suspected by the Paju Health Center. On February 22,2019 , as multiple cases were either confirmed or suspected in the same place and at the same time, the situation was judged to be an outbreak. Therefore, an epidemiological investigation was initiated to determine the size and source of infection and prevent further transmission. Since HAV infection can be transmitted by contaminated food or feces, it is crucial to rapidly find and block the source of infection $[1,9]$.

\section{Case Definition}

We defined a case as any individual who resided in or worked at facility $A$ and whose laboratory test results were positive for the anti-HAV IgM test, regardless of their symptoms, from December 12, 2018 (i.e., the day before the maximum incubation period for HAV infection-50 days), to the day of symptom onset of the primary case (i.e., February 9, 2019). The risk population was defined as all staff and residents belonging to facility $A$ during the period in which cases were confirmed and suspected. According to the Waterborne and Foodborne Infectious Diseases Management Guidelines of the Korea Disease Control and Prevention Agency, the rest of the residents and staff in facility A were defined as exposed (i.e., people who reside in the same place, regularly eat together, or share a toilet during the infectious period).

\section{Study Design and Response Measures}

A retrospective cohort study was conducted, including all residents and staff. Considering that the exposed individuals were strictly limited to facility $A$ and the size of this population did not change during the investigation period, a retrospective cohort study design was appropriate for this case. After identification of the outbreak and as per the instructions of the infectious disease investigator of Gyeonggi Province, data were collected on a history of common food consumption, genotype analysis of HAV from the cases, and water use (cooking, drinking, and living water). After collecting the above data, the following was carried out: an assessment of contact history and intensity between the residents and staff, HAV antibody testing for all exposed individuals, vaccination for people who were identified as being susceptible to HAV infection, isolation and medical treatment of people who showed HAV infection-related symptoms, and vaccination for people who did not belong to facility $A$.

\section{Data Collection and Analysis}

We obtained demographic and medical information on the at-risk population through face-to-face interviews. Due to the medical conditions of the residents, most of them were unable to converse; the investigator therefore collected general information mainly from the staff. We used R version 4.0.2 (https:// www.r-project.org/) for the statistical analyses.

\section{Ethics Statement}

The Institutional Review Board of Seoul National University Bundang Hospital exempted this study from review because the data in this study did not include any personal or identifiable information (X-2103-673-904).

\section{RESULTS}

\section{Outbreak Investigations}

From the onset of the index case's symptoms on February 8 , 2019, the outbreak lasted for 17 days and resulted in 9 cases of HAV infection (Figure 1). Not every case immediately underwent laboratory testing for HAV because 5 cases identified earlier visited different hospitals individually. After the outbreak was identified, on February 22, 2019, the infectious disease investigator of Gyeonggi Province ordered a screening test for all members of facility $A$, which identified 4 more cases. Exposure to the pathogen was assumed to have occurred between 


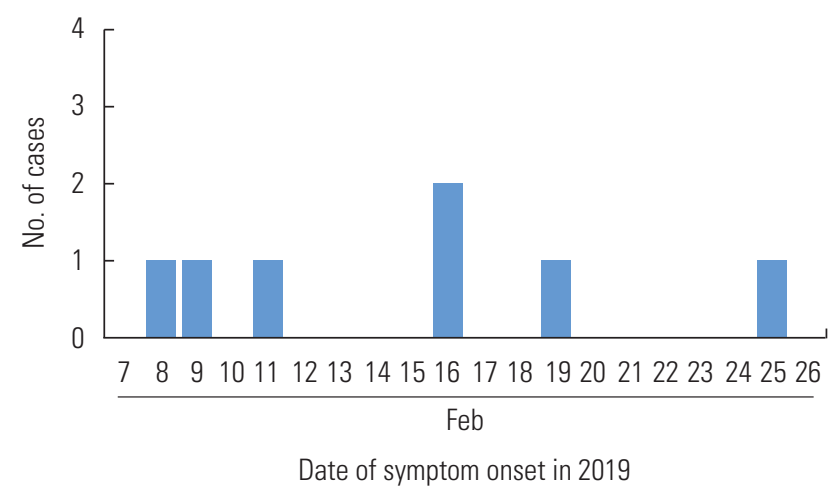

Figure 1. Date of symptom onset for the hepatitis A infection cases at facility A, Gyeonggi Province, Korea.

Table 1. Descriptive table of the hepatitis A outbreak in facility A, Gyeonggi Province, Korea

\begin{tabular}{lccc}
\hline Characteristics & $\begin{array}{c}\text { Cases } \\
(\mathbf{n = 9})\end{array}$ & $\begin{array}{c}\text { Risk population } \\
(\mathbf{n = 6 3 )}\end{array}$ & $\begin{array}{c}\text { Attack rate } \\
(\%)\end{array}$ \\
\hline Sex & & & \\
Female & 5 & 35 & 14.3 \\
Male & 4 & 28 & 14.3 \\
Age, range (y) & $32-51$ & $25-77$ & - \\
21-30 & 0 & 9 & 0.0 \\
$31-40$ & 7 & 16 & 43.8 \\
$41-50$ & 1 & 11 & 9.1 \\
$51-60$ & 1 & 18 & 5.6 \\
61-70 & 0 & 7 & 0.0 \\
Over 70 & 0 & 2 & 0.0 \\
Occupation & & & \\
Staff & 2 & 33 & 6.1 \\
Resident & 7 & 30 & 23.3 \\
\hline
\end{tabular}

January 1 and 31, 2019, considering that the incubation period of HAV is known to be 15 days to 50 days, with an average of 28 days, and the peak of the epidemic curve was located on February 15,2019 . The age of the at-risk population varied from 25 years to 77 years, while that of the cases varied from 32 years to 51 years (Table 1). The overall attack rate in facility A was $14.3 \%$. The attack rates were not significantly different according to sex. There were no confirmed cases in the age groups under 30 years and over 60 years. The 31-year to 40 -year age group showed the highest attack rate (43.8\%). The attack rates in the staff and residents were $6.1 \%$ and $23.3 \%$, respectively.

To identify the impact of disability and its related characteristics on HAV infection, we calculated the attack rate according to disability classification and related characteristics, including level of communication ability and requirement for assistance
Table 2. Attack rate of residents by classification of disability, level of communication ability, and requirement for assistance when eating in facility A, Gyeonggi Province, Korea

\begin{tabular}{lccc}
\hline Characteristics & $\begin{array}{c}\text { Cases } \\
(\mathbf{n = 7})\end{array}$ & $\begin{array}{c}\text { Risk population } \\
(\mathbf{n = 3 0 )}\end{array}$ & $\begin{array}{c}\text { Attack rate } \\
(\mathbf{\%})\end{array}$ \\
\hline $\begin{array}{l}\text { Classification of disability } \\
\quad \text { Intellectual disability }\end{array}$ & 5 & 20 & 25.0 \\
Physical disability & 1 & 3 & 33.3 \\
$\quad$ Both & 1 & 7 & 14.3 \\
Level of communication ability & & & \\
Communication possible & 1 & 8 & 12.5 \\
Challenged & 6 & 18 & 33.3 \\
$\quad$ Unable & 0 & 4 & 0.0 \\
Requirement for assistance when eating & & \\
$\quad$ Total assistance & 3 & 6 & 50.0 \\
Partial assistance & 1 & 3 & 33.3 \\
$\quad$ No assistance needed & 3 & 21 & 14.3 \\
\hline
\end{tabular}

when eating (Table 2). Regarding the disability classification, residents with physical disability had the highest attack rate (33.3\%). Likewise, those who had difficulties communicating fluently had a higher attack rate (33.3\%) than other groups defined by communication ability. Regarding the requirement for assistance while eating, residents who needed total assistance showed the highest HAV infection rate (50.0\%).

Among the 9 cases, 7 were symptomatic. The major symptoms in the 7 symptomatic cases were fever (77.8\%), nausea (55.6\%), jaundice, abdominal pain, vomiting, general weakness, and others (33.3\%), and abnormal urine (hematuria, oliguria). Six of 7 patients had a high fever (over $38^{\circ} \mathrm{C}$ ), and one had a fever of $37.8^{\circ} \mathrm{C}$. Minor symptoms included cough, headache, ascites, and anorexia.

To rule out person-to-person transmission, the contact history between each confirmed case was investigated. However, no epidemiological association between them was identified. It was found that all confirmed cases were located on the first floor of facility A; however, this was not a meaningful discovery because the second floor was mostly composed of rooms for staff (office), couples, or for common use.

\section{Laboratory Tests}

The laboratory test results of the samples are described in Table 3. On February 23 and February 25, 2019, all staff and residents were tested for HAV antibodies, which resulted in 3 additional IgM-positive cases. Among the 7 residents identified as HAV cases, stool polymerase chain reaction tests were 
Table 3. Hepatitis A antibody and PCR test results of residents and staffs in facility A, Gyeonggi Province, Korea

\begin{tabular}{lcccc}
\hline \multirow{2}{*}{ Classification } & \multirow{2}{*}{$\begin{array}{c}\text { Total } \\
\text { (n) }\end{array}$} & \multicolumn{3}{c}{ No. of positive cases } \\
\cline { 3 - 5 } & 49 & 3 & 29 & - \\
\hline Staff and residents & & $\mathbf{l g} \mathbf{M}$ & Stool PCR \\
\hline Temporary workers and volunteers & 5 & 0 & 5 & - \\
Cooks & 3 & 0 & 3 & 0 \\
Cases & 7 & - & - & $6(1 \mathrm{~A})$ \\
\hline
\end{tabular}

PCR, polymerase chain reaction; IgM, immunoglobulin M; IgG, immunoglobu$\operatorname{lin} G$.

also positive for 6 cases. HAV $1 A$ was suspected to be the causative pathogen of the outbreak. As the same HAV genotype was found in the groundwater, the source of infection was suspected-but not concluded - to be groundwater due to the unclear temporal order between the outbreak and the contamination of the groundwater.

Table 4 shows the seroprevalence of HAV antibodies. Among the commuting staff, $95.2 \%$ of individuals $(n=21)$ over 40 years old were positive for immunoglobulin $\mathrm{G}(\mathrm{lgG})$ antibodies against HAV; however, only 2 of 12 staff members under the age of 40 (16.7\%) had anti-HAV IgG antibodies. Among the residents, 10 of the 17 people aged over 40 years (58.8\%) were positive for IgG antibodies, and none of them had IgM antibodies. IgM antibody positivity was found in 2 staff members and 5 residents under 40 years of age, as well as in 2 residents aged over 40 years.

We also conducted laboratory tests on the environment of facility $A$, including samples collected from kitchens, living rooms, and other common places, as well as water. We found that the 15 samples collected from inside facility $A$ were negative for the pathogen; however, HAV $1 \mathrm{~A}$ was found in the groundwater that was used for bathing, washing, and cleaning.

\section{Environmental Investigation}

The inside of the cooking room was well divided into the inspection area, washing area, and pre-treatment area. Refrigeration and freezing temperatures were properly maintained, and no ingredients were past the expiration date. There were 3 cooks, all of whom had health certificates and were wearing sanitary clothes and hats while cooking, indicative of good health compliance. The staff and residents were served the same meals and ate in a shared dining facility. To rule out the possibility of transmission via food, the investigator also examined the menu served during the incubation period ( 50 days before and 14 days after symptom onset of the index case). The
Table 4. Hepatitis A antibody test results of residents and staff by age in facility A, Gyeonggi Province, Korea

\begin{tabular}{llcccc}
\hline $\begin{array}{c}\text { Staff/ } \\
\text { Residents }\end{array}$ & $\begin{array}{c}\text { Age } \\
\text { (y) }\end{array}$ & $\begin{array}{c}\text { Total } \\
\text { (n) }\end{array}$ & $\begin{array}{c}\text { IgM } \\
\text { positive }\end{array}$ & $\begin{array}{c}\text { IgG } \\
\text { positive }\end{array}$ & $\begin{array}{c}\text { IgG prevalence } \\
(\%)\end{array}$ \\
\hline \multirow{2}{*}{ Staff } & Under 40 & 12 & 2 & 2 & 16.7 \\
\multirow{2}{*}{ Residents } & Over 40 & 21 & 0 & 20 & 95.2 \\
& Under 40 & 13 & 5 & 0 & 0.0 \\
& Over 40 & 17 & 2 & 10 & 58.8 \\
\hline
\end{tabular}

IgM, immunoglobulin $\mathrm{M}$; IgG, immunoglobulin $\mathrm{G}$.

investigator then confirmed that raw food or salted seafood had never been served during the investigation period.

Tap water was used for cooking, while groundwater was used for kimchi, washing, cleaning, bathing, and other purposes until January 20, 2019, and was not used thereafter. The investigator strongly suspected that the kimchi made using groundwater was a potent source of infection; however, it had already been exhausted. For drinking water, a general water purifier located at the restaurant entrance on the first floor was used, and water purification was ensured by regular maintenance of the water purifier. Cups were used in a communal manner, wherein unused cups were stored in an ultraviolet sterilizer and used cups were collected in a tray above the sterilizer, and could be divided into before and after use.

The period of exposure was estimated, by considering the maximum incubation period of HAV infection, as extending from December 21, 2018 to February 28, 2019, the day when the symptoms of the index case began. This coincides with the time when groundwater was used, and a total of 9 patients were identified within 17 days from the first patient based on the onset of symptoms; therefore, the outbreak was suspected to be a single exposure related to groundwater use.

\section{DISCUSSION}

In this study, 9 individuals out of 33 staff members and 30 residents at a facility for the disabled were diagnosed with HAV 1 A infection in February 2019. According to the laboratory test results, groundwater was suspected to be the source of the outbreak, but this hypothesis was not confirmed due to a lack of information that clarified the temporal order of groundwater contamination and the HAV outbreak. Considering that the incubation period of HAV infection extends up to 50 days [1,7-9], the epidemic curve of this outbreak (Figure 1) showed a point source outbreak pattern. The overall attack rate at facili- 
ty A was $14.3 \%$, with the highest attack rate $(43.8 \%)$ among individuals aged 31-40 years, which is consistent with previous studies finding that younger adults are more vulnerable to HAV infection [10,17-19]. Considering that previous studies have explained the vulnerability of younger adults by lowered opportunity of exposure to naturally circulating pathogens due to improved sanitary and hygiene systems, the difference in the attack rate between staff and residents (6.1 and 23.3\%, respectively), implies that residents' relatively low opportunities for external or social activities resulted in higher susceptibility [17-19].

Furthermore, the difference between the staff and residents was especially pronounced when stratified by age, as shown in Table 4, which presents the differences in anti-HAV seroprevalence between the groups aged under and over 40 years. Intergenerational differences in anti-HAV seroprevalence have been discussed in several previous studies, but the magnitude of the differences found herein reinforces the importance of vaccination for vulnerable populations. The anti-HAV seroprevalence of the residents was lower than that of both the staff members and the general population $[3,17,20,21]$. Since people with physical and mental disabilities mostly cannot explain their conditions by themselves, further HAV outbreaks can occur in other residential facilities due to delayed recognition and identification [22]. Therefore, it would be helpful to immunize those working and living at facilities for the disabled.

The results for the attack rate of residents by classification of disability, level of communication ability, and necessity of assistance when eating reflects the possibility of person-to-person transmission. The reason for this is that physically disabled people generally require more direct contact with the staff. Furthermore, the necessity of assistance when eating showed consistent results, as the residents who required total assistance showed the highest attack rate (50.0\%). This result aligns with those of a previous study analyzing an HAV outbreak at a residential facility for disabled people in 2011, which found that the attack rate of the residents was significantly higher than that of the teachers or staff [23]. This result indicates a higher susceptibility of residents given an evenly distributed intensity of exposure in the high-risk population.

Even with the immediate response by the public health authorities, there are several limitations of this investigation and study. First, since regular checks for groundwater do not include HAV testing in Korea, it was difficult to clarify the temporal order of the incident, even though regular groundwater tests were never missed during the investigation period. The investigator examined the latest results of groundwater testing for facility $A$; however, it was irrelevant, as the results did not include HAV. Second, considering that HAV is transmitted mainly via the fecal-oral route, the most suspected source of infection, kimchi, could not be tested. At the time of investigation, the suspected kimchi had already been consumed by the staff and residents; therefore, the investigator could not request a laboratory test for the kimchi. Lastly, since most of the confirmed cases were disabled and unable to communicate fluently, it was difficult to track person-to-person transmission. Although the investigation was conducted with the hypothesis that there was an even level of exposure to pathogens in the risk population since the daily life of the residents was confined to facility A, an evaluation of person-to-person transmission could have enabled more accurate research results.

Despite these limitations, this study emphasizes the necessity of establishing infectious disease management policies, such as infection prevention management rules, systematic HAV antibody testing, and prioritization of vaccinations for staff and residents of facilities. People living in groups should be aware of the risk of exposure to HAV and should be proactively vaccinated.

\section{CONFLICT OF INTEREST}

The authors have no conflicts of interest associated with the material presented in this paper.

\section{FUNDING}

None.

\section{ACKNOWLEDGEMENTS}

We thank all public health officers of the Paju Health Center and microbiologists of the Gyeonggi Institute of Health \& Environment.

\section{AUTHOR CONTRIBUTIONS}

Conceptualization: CK. Data curation: YC, NK, JJK. Formal analysis: YC, CK, NK. Funding acquisition: None. Methodology: YC, CK. Visualization: YC, NK. Writing - original draft: CK, NK, JJK. Writing - review \& editing: YC, CK, HL. 


\section{ORCID}

Yeonhwa Chang https://orcid.org/0000-0001-5387-3399

Chanhee Kim https://orcid.org/0000-0003-0441-4107

Nayoung Kim https://orcid.org/0000-0002-0901-3305

Joon Jai Kim https://orcid.org/0000-0002-6133-8780

Heeyoung Lee https://orcid.org/0000-0003-4830-9851

\section{REFERENCES}

1. Lin KY, Chen GJ, Lee YL, Huang YC, Cheng A, Sun HY, et al. Hepatitis $A$ virus infection and hepatitis $A$ vaccination in human immunodeficiency virus-positive patients: a review. World J Gastroenterol 2017;23(20):3589-3606.

2. Kanda T, Jeong SH, Imazeki F, Fujiwara K, Yokosuka O. Analysis of 5 ' nontranslated region of hepatitis A viral RNA genotype I from South Korea: comparison with disease severities. PLoS One 2010;5(12):e15139.

3. Lee DY, Chae SJ, Cho SR, Choi W, Kim CK, Han MG. Nationwide seroprevalence of hepatitis A in South Korea from 2009 to 2019. PLoS One 2021;16(2):e0245162.

4. Martin A, Lemon SM. Hepatitis A virus: from discovery to vaccines. Hepatology 2006;43(2 Suppl 1):S164-S172.

5. Cristina J, Costa-Mattioli M. Genetic variability and molecular evolution of hepatitis A virus. Virus Res 2007;127(2):151-157.

6. Ching KZ, Nakano T, Chapman LE, Demby A, Robertson BH. Genetic characterization of wild-type genotype VII hepatitis A virus. J Gen Virol 2002;83(Pt 1):53-60.

7. Istre GR, Hopkins RS. An outbreak of foodborne hepatitis A showing a relationship between dose and incubation period. Am J Public Health 1985;75(3):280-281.

8. Shin EC, Jeong SH. Natural history, clinical manifestations, and pathogenesis of hepatitis A. Cold Spring Harb Perspect Med 2018;8(9):a031708.

9. Chakravarti A, Bharara T. Epidemiology of hepatitis A: past and current trends. In: Streba CT, Vere CC, Rogoveanu I, Tripodi V, Lucangioli S, editors. Hepatitis A and other associated hepatobiliary diseases. London: IntechOpen; 2020, p. 3-20.

10. Pak SC, Alastal Y, Khan Z, Darr U. Viral hepatitis in South Korea. Euroasian J Hepatogastroenterol 2017;7(2):163-165.
11. Kang SH, Kim MY, Baik SK. Perspectives on acute hepatitis A control in Korea. J Korean Med Sci 2019;34(36):e230.

12. Yoon JH, Cho SH, Kim DY, Yu SJ, Han KH. Epidemiological and clinical history of viral hepatitis in Korea. Infect Chemother 2021;53(1):159-165.

13. Lee SH, Yun JW, Lee JH, Jung YH, Lee DH. Trends in recent waterborne and foodborne disease outbreaks in South Korea, 2015-2019. Osong Public Health Res Perspect 2021;12(2):73-79.

14. Moon S, Han JH, Bae GR, Cho E, Kim B. Hepatitis A in Korea from 2011 to 2013: current epidemiologic status and regional distribution. J Korean Med Sci 2016;31(1):67-72.

15. Sohn YM, Rho HO, Park MS, Park JH, Choi BY, Ki M, et al. The changing epidemiology of hepatitis $A$ in children and the consideration of active immunization in Korea. Yonsei Med J 2000; 41(1):34-39.

16. Song MH, Lim YS, Song TJ, Choi JM, Kim JI, Jun JB, et al. The etiology of acute viral hepatitis for the last 3 years. Korean J Med 2005;68(3):256-260 (Korean).

17. Yoon JG, Choi MJ, Yoon JW, Noh JY, Song JY, Cheong HJ, et al. Seroprevalence and disease burden of acute hepatitis A in adult population in South Korea. PLoS One 2017;12(10):e0186257.

18. Kim K, Jeong BG, Ki M, Park M, Park JK, Choi BY, et al. The costs of hepatitis A infections in South Korea. Epidemiol Health 2014; 36:e2014011.

19. Ki M, Son H, Choi BY. Causes and countermeasures for repeated outbreaks of hepatitis A among adults in Korea. Epidemiol Health 2019;41:e2019038.

20. Choi R, Park MJ, Lee SG, Lee EH. Recent seroprevalence of antihepatitis A lgG in the Korean population: a large, populationbased study. Lab Med Online 2020;10(3):227-234.

21. Kim KA, Lee A, Ki M, Jeong SH. Nationwide seropositivity of hepatitis A in Republic of Korea from 2005 to 2014, before and after the outbreak peak in 2009. PLoS One 2017;12(1):e0170432.

22. Sher T, Stamper GC, Lundy LB. COVID-19 and vulnerable population with communication disorders. Mayo Clin Proc 2020; 95(9):1845-1847.

23. Lim HS, Choi K, Lee S. Epidemiological investigation of an outbreak of hepatitis $A$ at a residential facility for the disabled, 2011. J Prev Med Public Health 2013;46(2):62-73. 